\title{
Síndrome de la bolsa de orina púrpura. Presentación de un caso
}

\author{
Purple urine bag syndrome. Case report
}

\section{Resumen}

El síndrome de la bolsa de orina púrpura es una entidad poco frecuente que fue descrita por primera vez en el año 1978. Son factores relacionados con su aparición la edad avanzada, sexo femenino, cateterización urinaria crónica, constipación crónica, alcalinización de la orina y un alto contenido bacteriano en orina. Se produce cuando el producto derivado del aminoácido triptófano es metabolizado a sulfato de indoxil. Al encontrarse esta sustancia en una orina alcalina, mediante reacciones enzimáticas y de acuerdo a la concentración de oxígeno, cambia a índigo (azul) e indirrubina (rojo); los cuales precipitan en la orina y, junto con los materiales sintéticos del catéter y la bolsa urinaria, dan el color púrpura característico. Se presenta el caso de un varón adolescente de 17 años de edad, con antecedentes de paraplejia por lesión medular debida a proyectil de arma de fuego, que fallece en el domicilio sin asistencia médica. La paraplejia le obligaba al uso de sonda urinaria de forma permanente y al practicar la autopsia judicial se apreció un llamativo color púrpura en la bolsa colectora de orina.

Palabras clave: Bolsa urinaria. Cateterización urinaria. Infección de vías urinarias. Orina púrpura.

\section{Abstract}

The purple urine bag syndrome is a rare entity first described in 1978. Factors related to its production are elderly female, urinary catheterization, chronic constipation, alkaline urine and high bacterial levels in urine. It occurs when the product of the amino acid tryptophan is metabolized to indoxyl sulfate. This substance due to enzymatic reactions, in presence of an alkaline urine, and according to the oxygen concentration switches to indigo (blue) and indirubin (red), which precipitate in the urine and together with synthetic materials urinary catheter, give the characteristic purple color. We present the case of a 17-year-old male, with antecedents of paraplegia secondary a firearm wound, who died at home without medical care. Due to the paraplegic condition, chronic urinary catheterization was needed. At the judicial autopsy an amazing purple color in the urine bag was observed.

Key words: Urine bag. Urine catheterization. Urinary tract infection. Purple urine.

\section{Zanetti ${ }^{1}$ \\ V. $\mathrm{Ku}^{1}$ \\ J. Ruíz ${ }^{1}$ \\ E. González ${ }^{1}$}

${ }^{1}$ Médico Residente de Medicina Legal. Instituto de Medicina Legal y Ciencias Forenses. Ministerio Público. Panamá.

Correspondencia: Melayne Zanetti

E-mail:

melyzanetti@hotmail.com
Este texto forma parte de la comunicación presentada al

III Congreso Internacional de Medicina Legal y Ciencias Forenses (Panamá, 10-12 Octubre 2012), ganadora del primer premio en el concurso de carteles científicos.

\section{Introducción}

El síndrome de la bolsa de orina púrpura (SBOP) es una entidad poco frecuente descrita por primera vez en el año 1978 por Barlow y Dickson en un paciente al que se le colocó una sonda urinaria durante largo tiempo ${ }^{1}$. Consiste en la coloración púrpura de la bolsa colectora de orina producto de una serie de reacciones bioquímicas secundarias a la presencia de dos factores indispensables tales como la infección de vías urinarias dada por una alta carga de bacterias con propiedades fosfatasas-sulfatasas y la presencia de una bolsa colectora de orina.
Fecha de recepción: 20.NOV.2012

Fecha de aceptación:

11.ENE.2013 
Se produce cuando el producto derivado del aminoácido triptófano es metabolizado mediante una compleja serie de procesos bioquímicos a indoxil sulfato. Al encontrarse esta sustancia en una orina alcalina, mediante reacciones enzimáticas y de acuerdo a la concentración de oxígeno, cambia a índigo (azul) e indirrubina (rojo); los cuales precipitan en la orina y, junto con los materiales sintéticos del catéter y la bolsa urinaria, dan el color púrpura característico.

Presentamos un caso de este síndrome observado en la autopsia de un joven que sufrió una herida por proyectil de arma de fuego en columna vertebral dorsal. Como secuela de esta herida presentó una paraplejia y secundaria a la misma una severa infección de vías urinarias que, como se plasma en el informe médico de defunción, fue un factor contribuyente a la muerte del mismo.

Figura 1.

Catéter urinario conectado a bolsa colectora que contenía orina con un llamativo color púrpura. Se aprecia amplia úlcera de decúbito con signos de infección en la cadera izquierda.

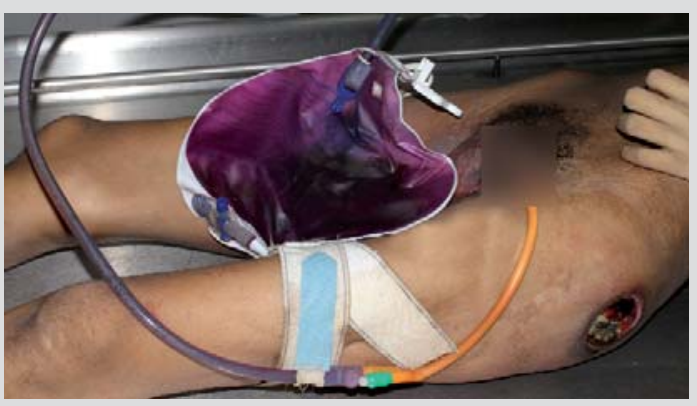

Figura 2. Riñón con escasa diferenciación córtico-medular y salida de material purulento a través de la pelvis renal.

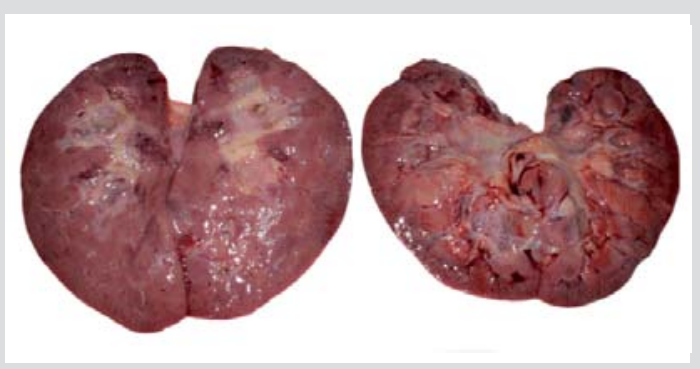

Figura 3. Vejiga urinaria con sedimento en su fondo de coloración crema verdoso de aspecto purulento.

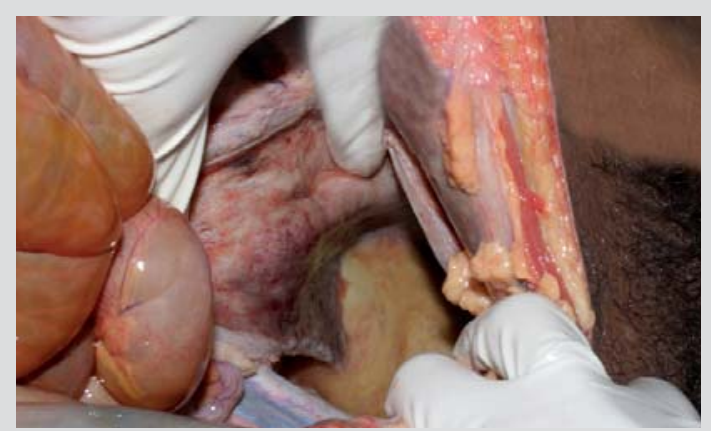

\section{Presentación del caso}

Varón de 17 años con antecedentes de paraplejia secundaria a herida por proyectil de arma de fuego a nivel de vértebra T1. Fallece en el domicilio sin asistencia médica por lo que fue ordenada una autopsia judicial.

a) Examen externo: atrofia de las cuatro extremidades y anquilosis de las manos, úlceras de decúbito con tejido necrótico a nivel bitrocantéreo y sacro. Cánula de traqueostomía a nivel cervical. Portaba catéter urinario conectado a bolsa colectora que contenía orina con un Ilamativo color púrpura (Figura 1).

b) Examen interno: encéfalo con notable aumento de peso ( $1.875 \mathrm{~g})$ con patrón de edema cerebral (aplanamiento de giros y circunvoluciones). Corazón de peso normal (325 g) con discreta dilatación de cavidades cardiacas derechas y presencia de trombos murales. Adherencias pleurales e interlobulares derechas y tromboembolismo pulmonar en la rama izquierda de la arteria pulmonar. Pulmones de peso discretamente elevado (D: 640 g; I: 600 g) con patrón de congestión y edema de moderado a severo. No se puso de manifiesto la presencia de infarto pulmonar. Riñones de peso normal (D: 180 g; I: 130 g) con escasa diferenciación córtico-medular, hemorragia en el área medular y áreas de coloración violácea con salida de material purulento a través de la pelvis renal (Figura 2). En la vejiga urinaria se cuantificaron 400 cc de orina turbia, olor fétido asociado a sedimento en su fondo de coloración crema verdoso con aspecto purulento (Figura 3).

c) Exploraciones complementarias:

- Análisis toxicológico negativo en muestras de sangre, orina y humor vítreo.

- Análisis microbiológico. En el cultivo del sedimento urinario se observó crecimiento de Proteus vulgaris.

d) Causa de la muerte: se consideró que el tromboembolismo pulmonar fue la causa inmediata de la muerte, la infección de vías urinarias como causa intermedia y la paraplejia como causa fundamental.

\section{Discusión}

EI SBOP es un fenómeno peculiar cuyo mecanismo exacto de producción es desconocido; no obstante, 
algunos autores han sugerido que una serie de procesos bioquímicos están involucrados en su génesis ${ }^{2,4,5}$.

El mecanismo de acción propuesto considera que este proceso se inicia cuando el triptófano, un aminoácido aromático esencial, es metabolizado por desaminación bacteriana (bacterias de la flora normal intestinal) a indol a nivel del intestino delgado, siendo absorbido y pasando a través de la circulación portal al hígado. En el hígado, mediante un proceso de conjugación, el indol se transforma a indoxil sulfato que se excreta por la orina y por acción de las enzimas bacterianas con propiedades sulfatasas/fosfatas se metaboliza a indoxil que se oxida produciendo índigo (coloración azul) e indirrubina (coloración roja). Estas sustancias al mezclarse y ante una orina alcalina y la presencia de un dispositivo de tubo y bolsa colectora de plástico, dan como resultado el color púrpura característico ${ }^{4,5}$ (Figura 4).

La prevalencia exacta del SBOP es desconocida ya que no se han realizado estudios con muestras significativas. Los escasos estudios publicados han sido realizados en centros de cuidado de ancianos y hospitales con muestras poco representativas, sin embargo, nos dan una frecuencia entre el $8,3 \%$ y el $27 \%$ en pacientes con cateterización urinaria crónica ${ }^{2,3}$. En la actualidad no contamos con datos acerca de su prevalencia publicados en Panamá y Latinoamérica.

Se ha descrito que la coloración púrpura en la bolsa colectora puede aparecer desde horas hasta días posteriores a la colocación del catéter urinario y que su coloración se hace más intensa a medida que pasa el tiempo y no se cambia la bolsa ${ }^{2,5}$.

La población con mayor riesgo de presentar este fenómeno es la de pacientes femeninas ancianas que cursan con largos periodos de cateterización urinaria, cuadros de constipación crónica e infección del tracto urinario $0^{6,7}$.

Se especula que la frecuencia es mayor en el sexo femenino debido a su anatomía genitourinaria; es decir, una uretra más corta propensa a ser colonizada y mayor contigüidad con el área anal ${ }^{4}$. También es frecuente en pacientes que padecen enfermedades crónicas tales como nefropatía diabética, insuficiencia renal crónica, enfermedad de Alzheimer, demencia y encamamiento por largos periodos de tiempo ${ }^{8}$.

La constipación crónica, que es muy frecuente en pacientes encamados, se ha comunicado en múltiples publicaciones y se relaciona tanto con el sobrecrecimiento bacteriano como con una disminución del tránsito intestinal, lo que permite aumentar la conversión de triptófano a indol y por ende la producción urinaria de sulfato de indoxil ${ }^{9}$.

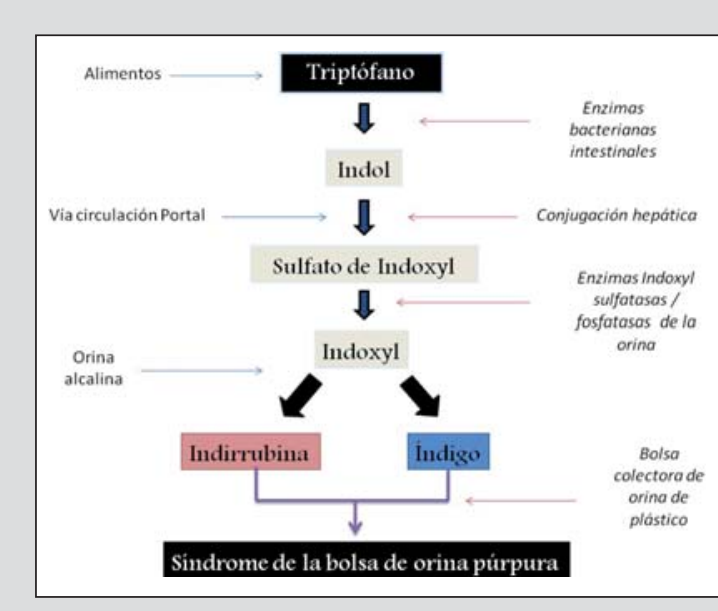

\section{Bacterias productoras de Enzimas Sulfatasa/ Fosfatasa}

- Providencia stuartii

- Providencia rettgeri

- Escherichia coli

- Proteus mirabilis

- Proteus vulgaris

- Morganella morganii

- Klebsiella pneumoniae

- Pseudomonas aeruginosa

La colonización bacteriana en orina se orienta a altas cargas de bacterias patógenas productoras de enzimas indoxil sulfatasa/fosfatasa (Tabla 1). Es interesante mencionar que la especie bacteriana no está directamente relacionada con la aparición de esta condición. La presencia de orina alcalina es una condición que se ha comunicado en la gran mayoría de estudios realizados, aunque se han descrito algunos casos en que ante la presencia de altos niveles de sulfato de indoxil y una alta carga bacteriana se puede dar el fenómeno en orina ácida ${ }^{10}$.

Un factor indispensable es la bolsa colectora de orina de plástico y se ha descrito en estudios una mayor frecuencia del fenómeno en aquellos pacientes que usaban bolsas del material cloruro de polivinilo (PVC) en comparación con aquellos que no la usaban. Se sugiere que el material en la superficie de la bolsa y el tubo colector reaccionan con el índigo e indirrubina, aunque no se ha establecido claramente cómo se da esta interacción ${ }^{8,11}$.
Figura 4.

Mecanismo propuesto para la producción del Síndrome de la bolsa de orina púrpura.

Tabla 1.

Bacterias productoras de enzimas sulfatasa/fosfatasa asociadas al sindrome de la bolsa de orina púrpura. 
Hay que tener en cuenta que existen condiciones que pueden producir un cambio en el color de la orina como son ${ }^{7}$ :

a) Ingesta de ciertos alimentos con colorantes.

b) Tintes como el azul de metileno.

c) Uso de medicamentos tales como: Amitriptilina (azul verdosa), Indometacina (azul verdosa), Doxorubicina (rojo), Propofol (verde).

d) Ciertas patologías como infección del tracto urinario por Pseudomonas (orina verde) y el síndrome del pañal azul (síndrome de Drummond), enfermedad autosómica recesiva muy rara que produce un defecto en la absorción de triptófano con aumento del indol que al oxidarse transforma la orina en color azul.

La importancia del presente caso radica en la rareza del mismo y en las implicaciones que puede tener sobre la persona que lo padece, ya sean psicológicas (ansiedad por el desconocimiento de su presentación) como clínicas (infección de vías urinarias) y sobre el personal médico ante la discrepancia sobre el tratamiento terapéutico.

Desde el punto de vista médico-legal, intentar conocer la génesis de estos hallazgos de tan rara frecuencia es una forma de mantenernos ávidos a la investigación y evitar alarmarnos ante dicha aparición, motivo por el cual presentamos este peculiar caso.

\section{Bibliografía}

1. Barlow GB, Dickson JAS. Purple urine bags [letter]. Lancet 1978; 1 (8057):220-1.

2. Dealler SF, Hawkey PM, Millar MR. Enzymatic degradation of urinary indoxyl sulfate by Providencia stuartii and Klebsiella pneumoniae causes the purple urine bag syndrome. J Clin Microbiol 1988;26:2152-6.

3. Hadano Y, Shimizu T, Takada S, Inoue T, Sorano S. An update on purple urine bag syndrome. Int J Gen Med 2012; 5(1):707-10.

4. Yamazaki, Y, Kobatake K. The purple urine bag syndrome. BMJ Case Reports 2009;2009 (doi:pii: bcr08.2009.2154).

5. Khan F, et al. Purple urine bag syndrome: an alarming hue? A brief review of the literature. Int J Nephrol 2011;2011:419213.

6. Mantani N, et al. A case- control study of purple urine bag syndrome in geriatric wards. J Infect Chemother 2003;9:53-7.

7. Tan CK, Wu YP, Wu HY, Lai CC. Purple urine bag syndrome. Can Med Assoc J 2008;179:491.

8. Chi-Hung L, Hsien-Te H, Chia-Chang C, DongSheng T, For-Wey L. Purple urine bag syndrome in nursing homes: Ten elderly case reports and a literature review. Clin Interv Aging 2008;3(4):729-34.

9. Lam TSK, Au CWK, Fun HT. Two cases of the purple urine bag syndrome. Hong Kong $j$ emerg med 2009;16:155-8.

10. Chung SD, Liao CH, Sun HD. Purple urine bag syndrome with acidic urine. Int J Infect Dis 2008;12(5):526-7.

11. Al-Sardar H, Haroon D. Purple urinary bag syndrome. Am J Med 2009;122(10):e1-2. 